IZA DP No. 9993

Evaluating the Impact of the Post-2008

Employment Subsidy Program in Turkey

Binnur Balkan

Yusuf Soner Baskaya

Semih Tumen

June 2016 


\title{
Evaluating the Impact of the Post-2008 Employment Subsidy Program in Turkey
}

\author{
Binnur Balkan \\ Central Bank of the Republic of Turkey \\ Yusuf Soner Baskaya \\ Central Bank of the Republic of Turkey \\ Semih Tumen \\ Central Bank of the Republic of Turkey, \\ ERF and IZA
}

\section{Discussion Paper No. 9993 \\ June 2016}

IZA

P.O. Box 7240

53072 Bonn

Germany

Phone: +49-228-3894-0

Fax: +49-228-3894-180

E-mail: iza@iza.org

Any opinions expressed here are those of the author(s) and not those of IZA. Research published in this series may include views on policy, but the institute itself takes no institutional policy positions. The IZA research network is committed to the IZA Guiding Principles of Research Integrity.

The Institute for the Study of Labor (IZA) in Bonn is a local and virtual international research center and a place of communication between science, politics and business. IZA is an independent nonprofit organization supported by Deutsche Post Foundation. The center is associated with the University of Bonn and offers a stimulating research environment through its international network, workshops and conferences, data service, project support, research visits and doctoral program. IZA engages in (i) original and internationally competitive research in all fields of labor economics, (ii) development of policy concepts, and (iii) dissemination of research results and concepts to the interested public.

IZA Discussion Papers often represent preliminary work and are circulated to encourage discussion. Citation of such a paper should account for its provisional character. A revised version may be available directly from the author. 


\section{ABSTRACT \\ Evaluating the Impact of the Post-2008 Employment Subsidy Program in Turkey*}

This paper investigates the employment effects of a targeted subsidy scheme implemented in Turkey following the 2008 crisis. The Turkish government started a subsidy program in 2008 to generate new employment for younger men and all women, which are the relatively disadvantaged groups in the Turkish labor markets. The program puts men of age 18-29 and all women into the treatment group, while men of age 30 and above are placed into the control group. We use a nationally representative micro-level dataset and a difference-indifferences approach to estimate the causal effect of this program. On aggregate, the subsidy program seems to be ineffective in increasing the employment probabilities of those individuals in the target group. However, when heterogeneity is accounted for by dividing the treatment group into several sub-groups, we observe that the program has been notably effective on some of those sub-groups. In particular, the increase in employment probability is high for older women, while a weaker positive effect is observed for younger women and almost no effect is detected for younger men. The effect on older women is subject to further heterogeneity: the program has increased the employment probabilities of low-educated and/or low-skill older women rather than the high-educated and/or high-skill ones.

JEL Classification: $\quad \mathrm{C} 21, \mathrm{H} 24, \mathrm{~J} 21, \mathrm{~J} 68$

Keywords: employment subsidies, treatment effects, difference-in-differences, Turkish micro data

Corresponding author:

Semih Tumen

Research and Monetary Policy Department

Central Bank of the Republic of Turkey

Istiklal Cad. No:10

06100 Ulus, Ankara

Turkey

E-mail: semih.tumen@tcmb.gov.tr

\footnotetext{
* We thank Thomas Lemieux, Insan Tunali, the participants of the SOLE/EALE Joint Conference in Montreal, IZA/World Bank Employment and Development Conference in Bonn, Turkish Economic Association Conference in Antalya, Koc Winter Workshop in Istanbul, IZA/CELSI Conference in Bratislava, and the seminar participants at Atilim University and the Turkish Ministry of Development for helpful comments. The views expressed here are of our own and do not necessarily reflect those of the Central Bank of the Republic of Turkey. All errors are ours.
} 


\section{Introduction}

In the past four decades, increased labor market gaps between the outcomes of the core groups (i.e., prime-age nonminority male workers) versus those of the disadvantaged groups (i.e., younger workers, females, and minorities) have called for policy interventions in the form of various labor market programs. One of the most popular policy recommendations raised for the purpose of reducing the observed gaps between these groups is to subsidize employers' costs of new hires from the disadvantaged groups relative to those from the core groups. ${ }^{1}$ The theoretical literature mostly agrees that this type of employer-side subsidies should be effective. ${ }^{2}$ However, empirical research testing this theoretical prediction is relatively rare and the existing evidence is mixed.

Our main goal in this paper is to provide new evidence on the causal effect of employerside subsidies by studying the impact of a program implemented in Turkey. In July 2008, the Turkish government started a labor market program to subsidize the employers' social security contributions. There were two target groups: (1) young men (of age between 18 and 29 ) and (2) all women above 18. The purpose of the program was to reduce the employment costs for the relatively disadvantaged groups in the labor market. The subsidy was available to those who were not employed as a tax-registered worker in the preceding 6 months and were hired in addition to the existing workers in the workplace, which means that generating new employment for the disadvantaged groups has been targeted rather than subsidizing the already filled positions. ${ }^{3}$

We estimate the effect of the subsidy program on the employment probabilities of those in the target group. The design of the subsidy program resembles a natural experiment that places older men (of age 30 and above) into the control group and the rest (i.e., the target groups) into the treatment group. To achieve our main goal, we perform a difference-in-differences (DID) estimation strategy in five steps. The first step takes the treatment group as a whole

\footnotetext{
${ }^{1}$ See, e.g., Kluve (2010) for a detailed discussion/comparison of the effectiveness of various labor market programs.

${ }^{2}$ See, for example, Kaldor (1936), Phelps (1994), Snower (1994), and Orszag and Snower (2003). See also Katz (1998) for a detailed review of the alternative theories.

${ }^{3}$ See Section 2 for the full details of eligibility and implementation.
} 
and evaluates the overall effectiveness of the program on employment probabilities of those in the target groups. At the second step, we divide the treatment group into three sub-categories: (i) young men (of age 18-29), (ii) young women (of age 18-29), and (iii) older women (of age 30 and above). This categorization allows us to investigate the potential mechanisms through which the program affects the employment probabilities. Third, we repeat these exercises by restricting our sample to individuals in narrower age categories, e.g., 25-35 and 28-31, to make sure that the result obtained in the entire sample is not an artifact of comparing the employment outcomes of young workers with those of the older ones. Fourth, we perform similar estimations conditioning on five education categories to check whether the program has been effective on any particular education level. Finally, similar to the estimates for education categories, we condition our regressions on the predicted skill levels of the workers to see if the program has been effective over a particular region on the skill distribution or over the entire distribution.

The main results can be summarized as follows. While our regressions indicate that the employment probabilities of the individuals in the target group have increased, on aggregate, around 1.5 percent after the subsidy relative to the control group, the estimates are not statistically significant suggesting that the employment subsidy program has only a negligible impact. The aggregate estimates, however, mask a considerable degree of heterogeneity, as we find that the effect of the program differs in sign and magnitude across treatment subgroups. To be concrete, we find that the subsidy program has a statistically significant positive impact - in the range of 2-2.5 percentage points - on the employment probabilities of women, particularly on older women. The effect on younger men, however, is close to zero and even slightly negative for some specifications. This suggests that the effects of the subsidy program are highly heterogeneous; that is, the labor market responds to incentives in a group-specific way rather than generating a homogeneous response. ${ }^{4}$

\footnotetext{
${ }^{4}$ The labor markets in Turkey has certain characteristics that might improve our understanding of the channels through which hiring subsidies might be affecting the employment probabilities. For example, female labor force participation rates have been increasing (which we appropriately control for) and there is a large market for informal employment. Moreover, Turkey has a considerable regional dispersion in the attitudes toward female employment. We mention these characteristics in detail further in the paper and our discussion of the empirical results links our estimates to these specific characteristics.
} 
We also explore the relevance of the idea that pooling younger and older workers together in the treatment and control groups may be further masking the impact of the program. For example, for workers of age 30 and above, the employment probabilities of those who are slightly above 30 may be responding to the subsidy in a systematically different way than the employment probabilities of those who are, say, above $50 .^{5}$ To address this concern, we restrict our sample first to those of age between 25 and 35, and, then, to those of age between 28 and 31. Similar to our results in the larger sample, the employment probabilities of younger men do not respond to the implementation of the subsidy program. For women, however, the responses are amplified. In particular, the employment rate of older women has increased approximately 4-4.5 percentage points; those of younger women have turned significant and reads around 3-3.5 percentage points relative to the treatment group.

We then ask the question whether there exists a further layer of heterogeneity across skill groups. To address this question, we condition our regressions first on education groups and, then, on predicted skill groups - where the predicted skills (or the "typical" wages) are constructed based on conditional Mincerian regressions reflecting region-, gender-, and yearspecific returns to schooling and labor market experience. We find that the effect on older females has mostly clustered around low-skill groups. In particular, the subsidy has increased the employment probabilities of older women with primary school degree and no school degree. In terms of the predicted skills, the program has mostly been effective at the second quartile of the skill distribution, which approximately corresponds to the minimum wage earners. Although we also see some significant coefficient estimates for more educated and/or skilled groups, the scale of these groups is small suggesting that a tiny set of individuals are affected. Since the results say that the positive employment effects have mostly been felt among lowskill older females, we conclude that the impact of the program is likely temporary due to low degree of labor market attachment for the individuals in this group.

The plan of the paper is as follows. Section 2 reviews the related literature in detail. Section 3 provides the institutional details of the subsidy program. Section 4 describes the data,

\footnotetext{
${ }^{5} \mathrm{~A}$ symmetric argument is valid for younger workers too.
} 
displays the recent trends in employment, gives the details of the characteristics of the labor markets in Turkey, outlines our econometric strategy, reports the estimates, and discusses the results. Section 5 concludes.

\section{Related Literature}

The post-2008 employment subsidy program in Turkey is an "employer-side hiring subsidy," a sub-category of the Active Labor Market Programs (ALMPs) implemented in many OECD countries to reduce unemployment. Employer-side subsidies have been implemented in various countries. One of the best-known programs is the one implemented in France in 1990s, which reduced the employer portion of the payroll tax for the low-wage workers. The main difference between the programs implemented in France and Turkey is that the French subsidy is given to all low-wage workers, while the Turkish subsidy does not impose any wage level for eligibility and, instead, it targets females and young males. As a result, estimating the causal effect of the program is easier for the Turkish case since the program clearly specifies the control and treatment groups, while the French program subsidizes all low-wage workers. The impact of the French program is estimated by several papers [see, e.g., Malinvaud (1998), Kramarz and Philippon (2001), Crepon and Desplatz (2002), and Cheron, Hairault, and Langot (2008)].

The general consensus in these papers is that the program has been effective in improving the outcomes of low-wage workers.

Belgium implemented a targeted subsidy program in the late 1990s - called the "Maribel subsidies." The target group was the manual workers. Unlike the French subsidy program, the program did not directly target low-wage workers. But, the ex post outcomes suggest that it operated mostly on low-wage workers. Goos and Konings (2007) report that the program has been effective in improving the employment prospects of those workers in the target group.

Another subsidy program was implemented by the Finnish government in 2006. Their subsidy program was similar to the French program in the sense that the target was low-wage workers. However, the Finnish program imposed an additional constraint: it focused on the older low- 
wage workers. Thus, identification of causal effects would be easier than the French case since there were clearly defined treatment and control groups amoung the low-wage workers. Huttunen, Pirtilla, and Uusitalo (2013) show, using a DID approach, that the employment subsidy program in Finland had no significant effect on employment probabilities of those workers in the target group.

There are also other subsidy programs implemented in different countries with different scope and coverage. For example, Blundell, Costa Dias, Meghir, and van Reenen (2004) find that hiring subsidies in the U.K. have increased the employment probabilities of those in the target group by around 5 percent, but this effect likely vanishes in the long-run. ${ }^{6}$ Deidda, Di Liberto, Foddi, and Sulis (2015) document using a propensity-score matching approach that employment subsidies in the Sicily region of Italy have significant effects on the employment probabilities of older and unskilled women. Boockmann, Zwick, Ammermuller, and Maier (2012) find using a DID strategy that hiring subsidies in Germany have partial effects, i.e., only on women in East Germany. ${ }^{7}$ Our findings are in line with the findings summarized above. Similar to Deidda, Di Liberto, Foddi, and Sulis (2015) and Boockmann, Zwick, Ammermuller, and Maier (2012), we find that the program implemented in Turkey mostly affects the employment outcomes of women. In particular, we find that the effect is more pronounced for older women. We also conjecture that the observed effect of the program would be stronger in the shortrun, but might decay over time since the program has been more effective for older women. In the Turkish labor market, there are reasons to believe that extra employment created for older women through subsidies might have been generated through hiring decisions based on favorable cost conditions rather than job suitability. This, in turn, might lead to increased incidence of mismatch in subsidizied hires; therefore, the expected duration of employment for these hires is low.

This is one of the few papers in the literature estimating the employment effects of hiring subsidy programs in Turkey. Our paper is directly related to two other papers focusing on

\footnotetext{
${ }^{6}$ See also De Giorgi (2005).

${ }^{7}$ See also Gruber (1997), Behagel, Crepon, and Sedillot (2008), and Korkeamaki and Uusitalo (2009) for some examples of the other relevant empirical work in the literature.
} 
evaluating the same subsidy program [see Uysal (2013) and Ayhan (2013)]. ${ }^{8}$ Similar to our paper, both of these papers implement DID strategies - the latter performs a DDD (tripledifference) exercise - and find that the program has somewhat been effective in increasing the employment probabilities of women. Specifically, Uysal (2013) uses aggregate labor market data by demographic groups and emphasizes that the program has been effective for older rather than younger women, while Ayhan (2013) uses micro-level data in order to control for individual factors relevant for employment outcomes and finds that the program has been effective in increasing the employment probabilities of women, but the effect lasted only a short period of time after the intervention.

Since we also perform our analysis with micro-level data, Ayhan (2013) is the closest paper to ours. However, our analysis is different from Ayhan (2013) in two important ways. First, Ayhan (2013) correctly points out the fact that the 2008 crisis may have a confounding effect. That said, she assumes that the effect of the crisis is the same for the two treatment groups (women and young men) and uses the third difference in the DDD exercise to eliminate the added worker effect due to the crisis. Instead of imposing such an assumption, we control for the potential impact of the crisis by including the regional unemployment rates as well as their interactions with each of the sub-groups in the target group. This alternative setup has three advantages: $(i)$ there is no need to invoke the "identical-crisis-impact" assumption for different groups targeted by the program, $(i i)$ we account for the region-specific impact of the crisis and the potential differences of this impact within the treatment categories, and (iii) we also account for the group-specific linear time trends to capture the inherent structural features of the labor markets in Turkey. Second, we ask whether the effect of the subsidy program has concentrated on a specific education category and/or a specific portion over the predicted skill distribution. This enables us to detect whether there exists a further layer of heterogeneity in our results.

\footnotetext{
${ }^{8}$ Betcherman, Daysal, and Carmen (2010) evaluate the effectiveness of other regional subsidy programs in Turkey.
} 


\section{Institutional Background}

\subsection{Policy Environment}

In the Turkish legislation, the non-wage cost of an employee to all contributing parties is 40.5 percent of the gross wage and this cost is shared between employer, employee, and the government as 18.5, 14, and 8 percentage points, respectively. This payment covers retirement benefits, the medical insurance contribution, and the unemployment insurance contribution. However, there exist subsidy opportunities, which reduce the social security contribution of employers significantly. Among those subsidies, regional subsidies, industry specific subsidies, or differential treatment of disadvantaged groups could be named.

In this paper, we focus the subsidies featuring differential treatment of the disadvantaged groups, which aim to improve labor market outcomes of women and young men. By the enactment of Law \#5763, initially, the relative social security contributions of related parties are updated. As the first part of Law \#5763, the employer portion of 18.5 percent is reduced to 13.5 for all workers. The remaining 5 percent is assumed by the government from that date on, updating relative shares to 13.5, 14, and 13 percentage points. Although that part of the change covers all current and prospective employees, an additional part of the program only aims young men of age 18-29 and women older than 18. What is important from the perspective of our analysis is that if an employee satisfies certain conditions together with age and gender criteria, Law \#5763 removes the employers' social security burden by adjusting the relative contributions of employer, employee, and the government as 0,14 , and 26.5 percentage points, respectively.

Law \#5763 aims at (i) discouraging informal employment by reducing the social security cost of formal employment by 5 percent for all workers and (ii) increasing the employment among the relatively disadvantaged groups in the labor market, i.e., women and youth by reducing the cost of hiring them to levels lower than that for men of age 30 and above. Since the differential treatment of youth and women comes from the second part of the subsidy, that part of the program will be the main point of interest in this paper. Law \#5838 has simply 
extended the subsidy registration period for young men and women, while its content stays similar to that of the Law \#5763.

A similar employment subsidy package is announced in February 2011 by the enactment of Law \#6111. It was announced that, between March 2011 and December 2011, the government would provide new cost-reducing opportunities to firms by covering all the social security payments of the new employees. In this program, new employee is defined as anyone who did not formally work in the last six months and the age, gender, and schooling of the employee would determine the duration of the subsidy. Similar to Law \#5763 and \#5838, women regardless of their age, and men under 29 years old get higher benefits under the program in comparison to men of age 30 and above. The differential treatment of women and young men in Law \#6111 is very similar to Law \#5763 and \#5838, since its main purpose could be summarized as reducing the social security cost of those groups below that of men of age 30 and above. The longest possible payment by the government was 48 months under this program, which covers women and young men who have vocational degrees. Therefore, Law \#6111 is considered as part of the program and analyzing the effects of post-2008 subsidies, i.e., those under Law \#5763, \#5838, and \#6111, constitutes the scope of this paper.

Finally, there were other subsidy programs designed to achieve higher investment in the relatively poor and underdeveloped regions, which are called as regional subsidies. However, these regional subsidies, provided under Law \#5084 in 2004 and \#5350 in 2005, were not designed to increase employment of any specific demographic group. Although these regional subsidies provide some benefits to the participants in terms of employment cost, these benefits are, by definition, mostly region-specific and are appropriately controlled in our empirical analysis by accounting for regional differences as well as their interactions with time and group-level effects.

\subsection{Design of the Program}

A cost-reducing subsidy targeting women and youth (between age 18 and 29) became effective in July 1st 2008 in Turkey. Although the program was initially introduced with one year 
participation period, the enactment of Law \#5838 extended the subsidy registration period to June 30th 2010. The target group of the 2008 subsidy was women and the youth who were not working in a formal job during the last six months and also would be hired as additional workers to the yearly average of pre-existing number of workers. Therefore, the program aimed at creating new jobs for women and youth without invoking the replacement of existing workers with the new ones. The policy takes the form of direct subsidy to employer by covering the employers' portion of the social security payment.

The design of the program is as follows: once a person is registered in the program, the employers' share of the social security payment corresponding to minimum wage is paid by government for five years. In terms of ratios, for the first year of the subsidy, the payment is fully covered by the government. For the following four years, the share of government payment decreases 20 percent each year, resulting in 20 percent payment in the fifth year of the subsidized employment and then the program terminates. "Payment corresponding to minimum wage" implies that the subsidy amount is fixed for everyone and total subsidy as a share of employers' cost goes down as the wage payment increases. For example, the benefit provided to the employer for a worker earning twice as the minimum wage will be half of the benefit provided for a minimum wage worker in relative terms. Therefore, there is a preferential treatment toward low-wage workers.

Different from Law \#5763 and \#5838, the subsidy program announced via enactment of Law \#6111 does not require payments corresponding to minimum wage and warrants 4 year full social security contribution coverage. However, as stated earlier, participation conditions of Law \#6111 are similar to Law \#5763 and Law \#5838, as it treats women and young men differently compared to men of age 30 and above. 


\section{Empirical Analysis}

\subsection{Data Description}

In this study, we use the Turkish Household Labor Force Survey (THLFS) data, which is compiled and published by the Turkish Statistical Institute (TURKSTAT). THLFS is a nationally representative micro-level dataset of households available at annual frequency. This cross-sectional dataset has around 4.5 million observations between the years 2004 and 2012, i.e., five hundred thousand observations per year, approximately. This rich individual-level dataset allows us to control for a large set of individual characteristics affecting individuals' employment outcomes such as age, gender, marital status, and education. All private households who are living in the territory of the Republic of Turkey are covered in the survey except the residents of schools, dormitories, kindergartens, rest homes for elderly persons, special hospitals, military barracks, and recreation quarters for officers. ${ }^{9}$

After excluding the individuals younger than 18 and older than $55^{10}$ and restricting the sample to non-agricultural individuals, our final sample covers around 2.1 million individuals, of whom 323,979 are women less than 30 years old, 671,830 are women of 30 and above, 276,979 are men less than 30 years old, and 639,324 are males of age 30 and above. We weight individual data by the frequency weights provided by TURKSTAT, which are calculated based on population projections. ${ }^{11}$

Next we clarify the terminology. The "target groups" or the "treatment group" correspond to age and gender groups, which are treated differentially under Laws \#5763, \#5838, and \#6111. Specifically, it refers to men between 18 and 29 years old and women older than 18 . Therefore, men of age 30 and above constitute the "control group" in our analysis, given that they are not eligible for subsidy. The subsidy period or, shortly, "subsidy" refers to the post-

\footnotetext{
${ }^{9}$ For more information about the survey, see TURKSTAT website which is available at www.turkstat.gov.tr.

${ }^{10}$ Mandatory schooling regulations and the retirement age for both men and women have changed over the sample period and, therefore, there is a probability that the excluded age groups' labor market outcomes are affected heavily by these changes. Therefore, we prefer to restrict our analysis to a smaller group of the sample. However, the results prevail when we include those groups back into the analysis.

${ }^{11}$ Until year 2009, the population projections were calculated based on the general population censuses. In 2007, "Address Based Population Registration System" (ABPRS) was established and there exists some differences in the distribution of population by age, sex, and regions in the ABPRS compared to the censuses. New population projections have started to be used in THLFS starting from January 2009 and onwards; and, for the sake of comparability, besides the annual results of 2004, annual and periodic results for 2005-2008 terms were revised by the new population projections.
} 


\begin{tabular}{l|c|c} 
& \multicolumn{2}{|c}{ Employment Rates } \\
\hline & Pre-Subsidy & Post-Subsidy \\
\hline \hline Male $<30$ & 0.7064 & 0.6993 \\
Female $<30$ & 0.2610 & 0.2937 \\
Female $\geq 30$ & 0.2363 & 0.2801 \\
\hline \hline
\end{tabular}

Table 1: Employment Rates: The average employment rates before and after the program.

2008 period since the Law \#5763 was enacted in mid-2008. Appendix A provides detailed information about the rest of the control variables.

Finally, to control for the local reflections of aggregate fluctuations, such as the regional business cycles, we embed the yearly regional NUTS-2 level unemployment rates into our dataset. This is crucial for capturing the cyclical macro variations in labor markets, which may also vary across regions as well. In fact, this might be the case given the lowest regional unemployment rate is below 5 percent and the highest is around 15 percent based on the 2011 data. Since residency is reported at the NUTS-2 level, we manage to match each individual to the related labor market circumstances and proxy the effects of regional business cycles on labor market outcomes using this information.

\subsection{Prior Trends}

Before presenting the results of our econometric analysis, we present some information on the employment outcomes of the target group of the program by using quarterly macro-level data, which are compiled and published by the TURKSTAT. ${ }^{12}$

As Table (1) clearly demonstrates, when the group-level averages of seasonally adjusted employment to population ratios for women and young men are examined, the rise in the employment probabilities of older women is more pronounced in the post-subsidy period and reaches to almost 5 percentage points. Moreover, women less than 30 years old gain 3 percentage points, whereas, the employment to population ratios of young men stayed roughly constant between pre- and post-subsidy periods, on average. Therefore, for women in all age groups,

\footnotetext{
${ }^{12}$ Given that employment is subject to a high degree of seasonality, we first carry out seasonal adjustment for the employment to population ratios for all age and gender groups for the interval 2004-2012. Therefore, we end up with 14 seasonally adjusted series representing employment to population ratios of the related age and gender categories.
} 
there is a clear difference between before-subsidy and after-subsidy outcomes, which refers to a trend break at the time of the subsidy declaration. For young men, there also exists a discrepancy between before-subsidy and after-subsidy periods; but, this change seems to be negative.

Although the trend break is visible, it is important to verify that these changes are indeed due to the subsidy implementation rather than being a part of an ongoing trend or some other event happened between 2004 and 2012. We subtract the employment to population ratio of men of age 30 and above from the employment to population ratio of each of the treatment sub-groups to see if there are any relative trends carried from the pre-program period. As Figure (4.1) shows, there are important upswings in the relative employment of women after mid-2008, which also dominate the overall employment outcome in the target group. However, while young males seem to gain some position in the labor market with respect to older ones before 2008, their relative position have not visibly changed in the post-2008 period. Hence, our findings regarding prior trends confirm the existence of a break around the time of the subsidy.

The absence of positive trends in the pre-2008 period for the employment rate of target group can be regarded as an evidence that the differentiation took place around the time of the subsidy rather than occuring as part of an ongoing trend. This observation raises additional questions about the possible added worker effects due to recent global financial crisis, which roughly coincides with the timing of the subsidy. However, the macro-level series presented in Figure (4.1) do not allow us to differentiate the effect of the subsidy from the other potential effects. To make more accurate judgements about the potential added worker effects, a detailed microeconometric analysis is needed, which we present next.

\subsection{Econometric Model}

The differential treatment of the employment subsidy program in the post-2008 period to the females and young males allows us to assess the effects of the program by employing a difference-in-differences (DID) strategy. In particular, the program focuses on reducing the 

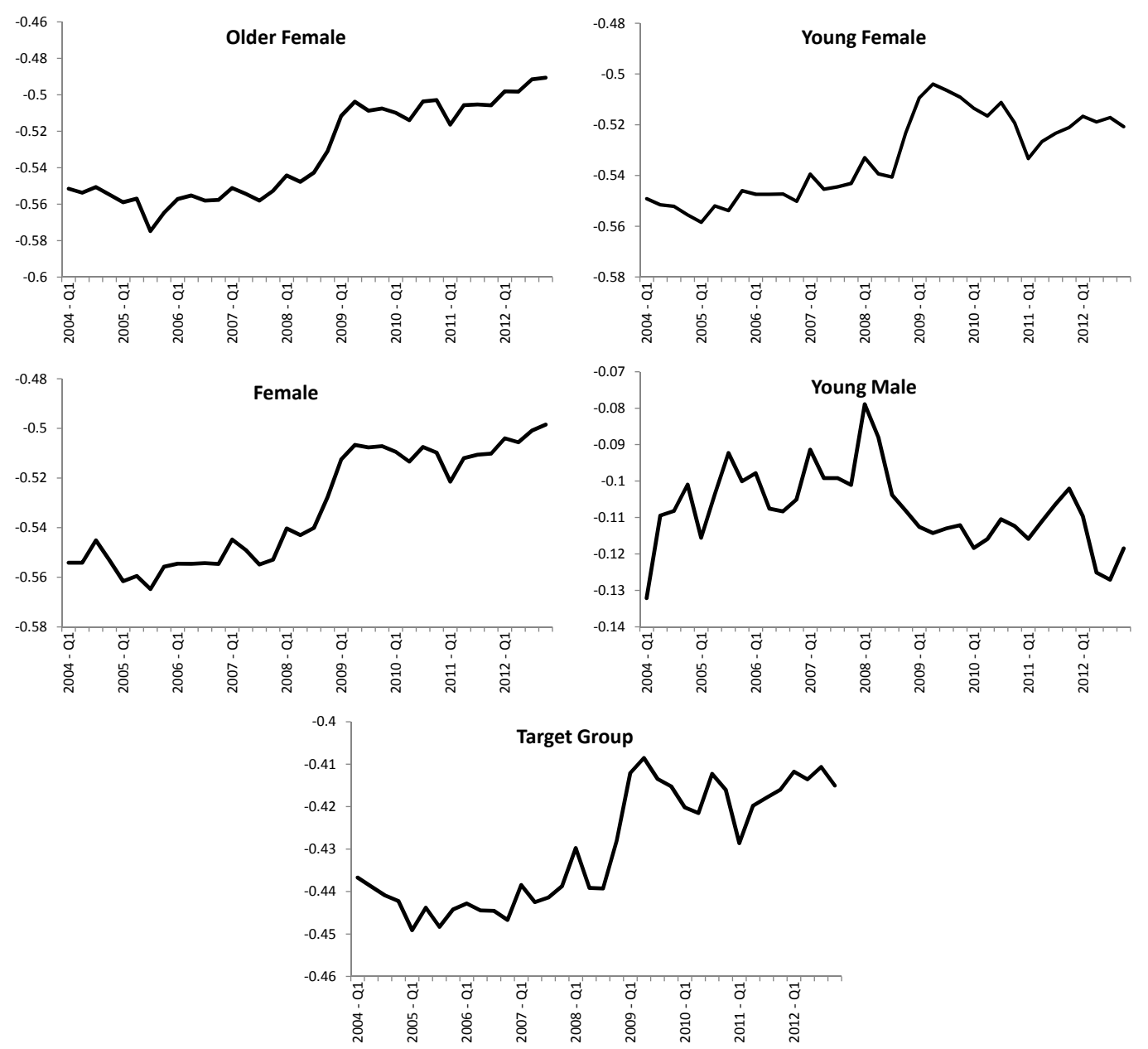

Figure 4.1: Relative Employment to Population Ratios for the Selected Subsidy Receiving Groups. This figure plots the employment to population ratios of the workers in the indicated treatment groups relative to the employment to population ratio of males of age 30 and above (i.e., the control group). The increase in the values in 2008 implies that the corresponding subsidy-receiving group strengthens its position in the labor market relative to the non-recipient group. Young and old mean below age 30 and above age 30, respectively.

employers' social security contribution cost for the males of age 18-29 and all females of age above 18. As stated earlier, the employment subsidy program focusing on these demographic groups consists of Law \#5763 effective as of July 2008, Law \#5838 effective as of February 2009, and Law \#6111 effective as of February 2011. Considering the annual nature of our dataset, we define the binary variable subsidyt, which takes the value of 1 for the 2008-2012 period and zero for the years before 2008 .

We assess the impact of the program in three steps. First, we focus on whether the subsidy program has resulted in a differential increase in the employment probabilities of the target group without differentiating with respect to the ages or the gender of the individuals. We 
define the binary variable target $_{i}$ as a binary variable equal to 1 if an individual is a male of age 18-29 or female, and 0 if the individual is in the control group, i.e., a male of age above 30, who are not eligible for the employment subsidies. In particular, we estimate:

$$
\begin{aligned}
E_{i, r, t} & =\beta_{0}+\beta_{1} \cdot \text { target }_{i}+\beta_{2} \cdot \text { target }_{i} \times \text { subsidy }_{t}+\gamma \cdot X_{i, t}+\alpha_{1} \cdot U R_{r, t} \\
& +\alpha_{2} \cdot \text { target }_{i} \times U R_{r, t}+\alpha_{3} \cdot \text { target }_{i} \times \text { time }+\theta_{r}+\theta_{t}+\theta_{r} \times \theta_{t}+u_{i, t},
\end{aligned}
$$

where $E_{i, r, t}$ is a binary variable equal to 1 if the individual is employed and 0 otherwise, $\boldsymbol{X}_{i, t}$ is the vector of personal characteristics, such as age, education, martial status, and $U R_{r, t}$ is the unemployment rate of the region of individual's residence, $r$, in year $t$. In addition, $\theta_{r}$ and $\theta_{t}$ are region and year fixed effects, respectively.

We also control for other factors, which might otherwise contaminate the differential employment effect of the program on the target group. These include the interactions between regional unemployment rates and the target group indicator, differential time trend for the target group, and the region-year fixed effects. The first one allows for the possibility that the individuals in the target group might have become employed as a result of an added worker effect due to the deterioration in the overall economic activity and labor market conditions in 2008-2009 global economic crises. ${ }^{13}$ The differential time trends for the target groups account for the changes in the employment rate of the target group, particularly due to females, which have been going on since mid-2000s [Tayfur and Kirdar (2011)]. These also partly account for the possibility that the sectors with different degrees of skill complementarity for the young and female workers might have grown and created employment at a different rate. Finally, the region-year effects, i.e., the interactions between region fixed effects and the year fixed effects, capture the time-varying region-specific characteristics relevant for the employment outcomes. These control for factors like regional macroeconomic developments or regional employment subsidies given under Law \#5084 in 2004 and Law \#5350 in 2005, which do not have exclusive focus on the target groups determined by Laws \#5763, \#5838, and \#6111 but still might have differentially affected them. ${ }^{14}$

\footnotetext{
${ }^{13}$ See Baslevent and Onaran (2003) for evidence on added worker effects in Turkey.

${ }^{14}$ Betcherman, Daysal, and Carmen (2010) show the positive impact of these two regional incentives on employment by using
} 
The parameter of interest in Equation (4.1) is $\beta_{2}$, which simply gives us the differential percentage point change in employment rates of the individuals in the target group relative to the control group. A positive and significant estimate for $\beta_{2}$ suggests that the difference between the employment rates of the control group and the treatment group has declined following the employment subsidy program.

At the second step, we define male $1829_{i}$ as a binary variable equal to 1 if individual is a male of age 18-29 and 0 otherwise, and female $_{i}$ as a binary variable equal to 1 if individual is a female and 0 otherwise. We then estimate the differential impact of the program on the employment probabilities of these two groups with the following equation:

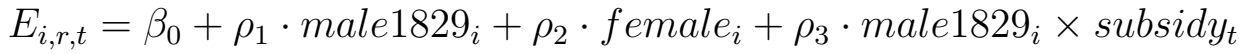

$$
\begin{aligned}
& +\rho_{4} \cdot \text { female }_{i} \times \text { subsidy }_{t}+\gamma \cdot X_{i, t}+\alpha_{1} \cdot U R_{r, t}+\alpha_{2} \cdot{\text { male } 1829_{i} \times U R_{r, t}} \\
& +\alpha_{3} \cdot \text { female }_{i} \times U R_{r, t}+\alpha_{4} \cdot{\text { male } 1829_{i} \times \text { time }+\alpha_{5} \cdot \text { female }_{i} \times \text { time }} \\
& +\theta_{r}+\theta_{t}+\theta_{r} \times \theta_{t}+u_{i, t}
\end{aligned}
$$

The parameters of interest in Equation (4.2) are $\rho_{3}$ and $\rho_{4}$, which are respectively equal to the differential change in the employment rates of the young males and females relative to the males of age 30 and above. Similar to Equation (4.1), the Equation (4.2) also allows for added worker effects for the female and the young males, albeit at different magnitudes, as well as different linear time trends for these two demographic groups.

Finally, we consider a specification in which we also assess whether the young and old females have experienced different employment gains following the subsidy program. This specification also allows for different degrees of added worker effects and linear time trends for the young

province-level data. 
females, old females, and young males:

$$
\begin{aligned}
E_{i, r, t} & =\beta_{0}+\phi_{1} \cdot \text { male } 1829_{i}+\phi_{2} \cdot \text { female } 1829_{i}+\phi_{3} \cdot \text { female } 3055_{i}+\phi_{4} \cdot \text { male } 1829_{i} \times \text { subsidy } \\
& +\phi_{5} \cdot \text { female } 1829_{i} \times \text { subsidy }+\phi_{6} \cdot \text { female } 3055_{i} \times \text { subsidy } y_{t}+\gamma \cdot X_{i, t}+\alpha_{1} \cdot U R_{r, t} \\
& +\alpha_{2} \cdot \text { male } 1829_{i} \times U R_{r, t}+\alpha_{3} \cdot \text { female } 1829_{i} \times U R_{r, t}+\alpha_{4} \cdot \text { female } 3055_{i} \times U R_{r, t} \\
& +\alpha_{5} \cdot \text { male } 1829_{i} \times \text { time }+\alpha_{6} \cdot \text { female } 1829_{i} \times \text { time }+\alpha_{7} \cdot \text { female } 3055_{i} \times \text { time } \\
& +\theta_{r}+\theta_{t}+\theta_{r} \times \theta_{t}+u_{i, t}
\end{aligned}
$$

where female $1829_{i}$ is equal to 1 for females of age $18-29$ and 0 otherwise, and female $3055_{i}$ is equal to 1 for females of age 30-55 and 0 otherwise. In this specification, $\phi_{4}, \phi_{5}$, and $\phi_{6}$ give, respectively, the differential changes in employment rates of males between 18-29, females between 18-29, and females between 30-55 years old relative to the control group.

\subsection{Estimation Results}

\subsubsection{Results for the 18-55 Age Group}

Table (2) shows the results for the specification in Equation (4.1), where the reported estimates are probit marginal effects. In the first column, we control for all factors except for the different time trends for the employment of the target group and the region-year fixed effects. These results indicate that the employment gap between the target group and the control group has declined by 1.7 percentage points following the employment subsidy program. These results also confirm the presumption that the employment of the individuals in the target group might have displayed an added worker effect, as the differential effect of an increase in the regional unemployment rates on the employment of the target group is positive. However, as stated earlier, this specification does not control for already existing trends in the employment rates of the target groups as well as regional variations in employment rates that potentially vary across years. By allowing for these effects in Columns 2 and 3, we observe that the positive differential effect of the employment subsidies on the target group becomes smaller and statistically insignificant mainly due to controls for the differential time trends. Hence, 
the results for the 18-55 age group suggest that the effect of the subsidy program on the overall employment of the subsidy group turns insignificant after controlling for the added worker effects.

In Table (3), we treat females and young males differently. The column 1, where we do not allow for the different time trends and added worker effects for the demographic groups, suggests that the program leads to a 4.4 percentage point improvement in the employment probabilities for females and no visible (even negative) improvement for young males relative to the males of age 30 and above. However, introducing the differential time trends appears to be important again in the sense that the estimate for the relative improvement in employment rates for females becomes 2.3 percentage points, albeit statistically insignificant. Finally, when we introduce the region-year fixed effects, we find that females have enjoyed 2.2 percentage point increase in employment rates relative to the males of age 30 and above, whereas the young males have not experienced any relative improvement.

Finally, we assess the differential effect of the program on the employment probabilities of young males, young females, and old females in Table (4) by following the convention in Tables (2) and (3). Again, the specification without controls for differential time trends and the region-year effects yields estimates suggesting that the program has resulted in a sizable and statistically significant improvement in the employment probabilities of the young and old females. However, controlling for the group-level differential time trends and the regionyear effects, we find that only females who are of 30 years of age or older have experienced significant employment gains due to the program. In particular, we observe that individuals in this category have experienced 2.5 percentage point increase in employment probabilities relative to the males of age 30 and above.

\subsubsection{The Results for the Narrower Age Groups}

While the results presented above suggest that older women have been the only group of individuals who have enjoyed the employment benefits of the targeted subsidies introduced in the post-2008 period, there is one particular factor that may contaminate the results presented 
so far. In particular, having used a wide range of ages, i.e., from 18 to 55, the estimations presented so far may insufficiently control for the unobserved heterogeneity across individuals. For example, the labor supply behavior of an 18 year-old male or a female may differ substantially from that of the males or the females in the 30-55 age group. ${ }^{15}$ Therefore, we focus on narrower age groups, first 25-35 and then 28-31, which may be more homogenous in terms of age-related unobserved heterogeneity that may be relevant for their labor supply behavior or any other unobserved factor related to their employment outcomes.

Table (5) presents the results controlling for the differential linear time trends and the regionyear fixed effects for the 25-35 age group in three specifications different from each other in terms of how the treatment group is defined. In Column 1, the indicator for the treatment group, i.e., target, includes all females in the 25-35 age group and males in the 25-29 age group, whereas the control group is the males in the 30-35 age group. The Column 2 differs from Columns 1 as it explicitly specifies the females in the 25-35 age group and males in the 25-29 age group. Finally, the Column 3 explicitly specifies the females in the 25-29 age group, females in the 30-35 age group, and males in the 25-29 age group. While these results also confirm the existence of a positive employment effect for the older females and no visible effect for the younger males, they differ from the previous ones for indicating a positive and significant employment effect for the younger females. In particular, Column 3 suggests that the employment gain for the younger females and older females has been 3.2 percentage points and 4.8 percentage points relative to males of age 30 and above.

Finally, in Table (6), we focus exclusively on the individuals in the 28-31 age group. These results also reveal a similar picture in the sense that the employment of individuals who are in the target group - defined in the broad sense - have experienced a 3 percentage point higher increase relative to males in the 30-31 age group. Considering the possible heterogeneities within the target group, we observe that the effect on the young males has been non-negligible, while the employment of females in the 28-29 age group and females in the 30-31 age group

\footnotetext{
${ }^{15}$ For example, Neal (1999) argues that new entrant young individuals shop for jobs and firms in the labor market early on, while they start shopping for careers once they get experienced. Another alternative is that the standard life-cycle effects might lead to behavioral differences across young and old individuals.
} 
has increased by 3.8 percentage points and 4.1 percentage points relative to individuals who were not eligible for the subsidies.

\subsubsection{Effects of the Program by Education and Predicted Wage Groups}

Finally, we aim at providing some evidence on the effect of the employment subsidies by education groups and the predicted wage categories. This exercise is important for assessing two points. First, the nature of the initial subsidy program is such that the net amount of employment subsidy is maximized for the minimum wage workers and decreases monotonically as the wage of the individuals increase. Therefore, it may be crucial to see whether the effect of the program on the individuals at different regions of the wage distribution is different from each other. Second, related to the first point, it may be important to have a general sense of whether the program has been effective for all education and/or skill groups in the working population or it has produced to more specific effects. This question also has some implications for whether the program has increased the employment of those who may have more likelihood of remaining in the workforce once the monetary subsidies fade away.

We carry out this exercise in two steps. First, we group the individuals in 5 education categories, namely the individuals without any diploma, with primary school diploma, with secondary school diploma (i.e., at typically 8 years of schooling), with high school or vocational school diploma (i.e., typically 11 years of schooling), and with college degree or above, and explore the differential effect of the subsidies on the employment of the target group using sub-samples corresponding to these employment categories. Second, since we can only observe the wages of those who are employed, we predict the wages of all individuals using a Mincerian wage regression estimated with the sample of individuals with observed wages. Then, we estimate the effect of the program using sub-samples corresponding to different quartiles of the predicted wage distribution.

The Results for the Education Groups Table (7) presents the estimation results by education groups for the 18-55 sample. We observe that the older women within the "no diploma" category, "primary school graduate" category, and the "college graduate" category appear 

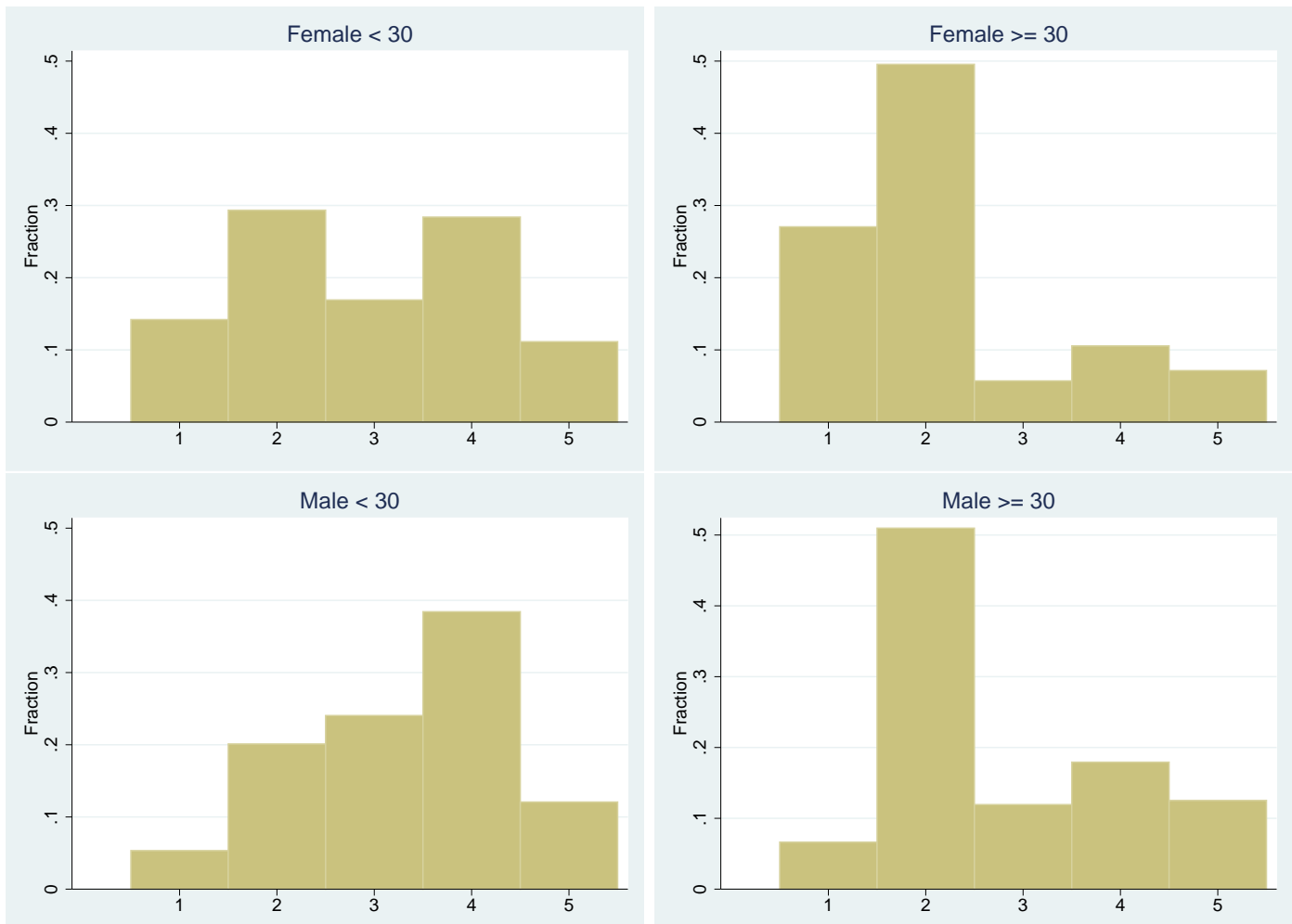

Figure 4.2: Distribution of Education by Sub-groups. Education level 1 refers to no degree, level 2 primary school, level 3 secondary school, level 4 high school (including vocational high school), and level 5 college degree \& above.

to have significant employment gains relative to the males of age 30 and above within these education groups. In terms of the shares of individuals in these education categories, we observe that "primary school graduates" is the category with highest number of individuals, and the college graduates and the individuals with no diploma are the categories with the least number of individuals, respectively. The females less than 30 years old have experienced relative employment gains within the "high school or vocational school graduates" category, which is the second largest education group. The estimation results for the 25-35 sample, presented in Table (8), also indicate older female within the "individuals with no diploma" and "primary school graduate" categories as having relative employment gains considering the males of age 30 and above. Looking at these results, we conclude that the employment effects that we presented in the preceding sections mostly come from the older women with at most primary school degrees. 
The Results for the Predicted Wage Categories We also assess whether the program has affected the individuals differently with respect to where they are located over the wage distribution. However, since we do not observe the wages of the individuals who do not work, we proxy the wages of all individuals with their predicted Mincerian wages, obtained from estimating:

$$
\begin{aligned}
\ln W_{i, r, t} & =\beta_{0}^{g, r, t}+\beta_{1}^{g, r, t} \cdot E d u c_{i, t}+\beta_{2}^{g, r, t} \cdot A g e_{i, t}+\beta_{3}^{g, r, t} \cdot A g e_{i, t}^{2} \\
& +\beta_{4}^{g, r, t} \cdot \text { Married }_{i, t}+u_{i, r, t},
\end{aligned}
$$

where $W_{i, r, t}$ is the net (after-tax) monthly wage and salary income of individual $i$ at region $r$ in year $t, E d u c_{i, t}$ is the vector of binary variables representing mutually non-overlapping education categories, $A g e_{i, t}$ and $A g e_{i, t}^{2}$ are the age and its square and Married $_{i, t}$ is a binary variable equal to 1 if the individual is married and 0 otherwise. We run the separate Mincerian wage regressions for the year-region-gender combinations, which account for the fact that the returns to schooling, experience, marital status, or labor market conditions may be different across time, geographical regions, or gender groups. For example, $\beta_{1}^{g, r, t}$ represents the returns to schooling for gender group $g$ at region $r$ in year $t$.

Tables (9) and (10) present the results for the impact of the program for 18-55 and 25-35 samples. A number of important observations arise from these results. First, we do not see any employment effect for the individuals within the first quartile of the predicted wages. Remember that our wage prediction exercise includes the ones who are out of the labor force; therefore, the ones for whom the labor market valuations are potentially quite low due to low skill levels. The predicted wages for this group are typically below the minimum wage level and do not reflect the actual wages earned in the labor market. The second quartile of the distribution accomodates the interval in which the minimum wage levels fall. This suggests that we do not see any effect on workers whose skill levels are below the skills of the typical minimum-wage workers. Second, considering the 18-55 sample, we find that the program did not provide positive employment effects also for the individuals within the 4th quartile of the predicted wage distribution. 

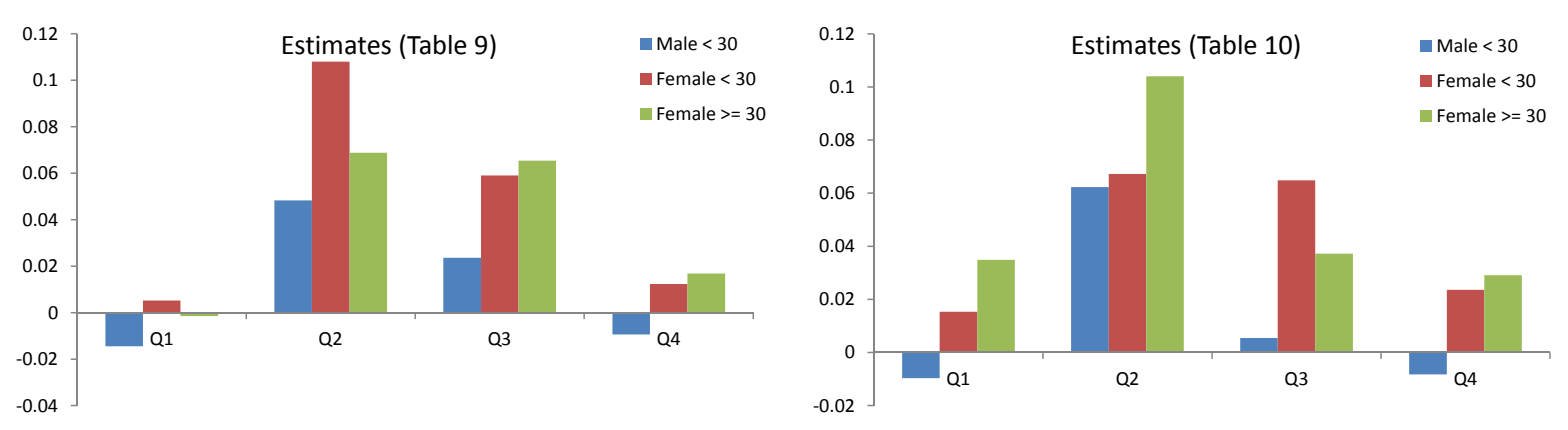

Figure 4.3: Estimates by the Predicted Wage Quartiles.

Finally, both for the 18-55 and 25-35 samples, we observe that the effect of the program on the employment of all the individuals in the target groups decreases as we move towards higher predicted wages. For example, considering the results with 18-55 sample, the employment of the older females in the second and third quartiles increased by 6.9 and 6.5 percentage points relative to the males of age 30 and above within the corresponding predicted wage quartiles, while there is no differential change observed in the fourth quartile. The relative employment increases for the younger women in second and third quartiles have been 10.8 and 5.9 percentage points respectively, with no significant employment gain in the fourth quartile. The employment of the young males within the second quartile increased by 4.8 percentage points relative to male above 30 , with no significant changes in the third and fourth quartiles. A similar pattern, i.e., almost monotonically decreasing effect with higher predicted wages, can be observed in Table (10) as well. As an example, the relative employment gains of women in the 30-35 age category compared to men in the 30-35 age category have been 10.4 percentage points, 3.7 percentage points, and 2.9 percentage points within the second, third, and fourth quartiles of the predicted wage distribution, respectively. Figure (4.3) visualizes these estimates.

\subsubsection{A Regression Discontinuity Design Exercise}

The subsidy program sets 30 as the cutoff age level, which means that there is scope for implementing a regression discontinuity design (RDD) exercise. However, this scope is quite limited since the age cutoff is binding for men only. In other words, the subsidy is provided to all women above age 18, while, for men, it is provided only to those below age 30 and this 
suggests that the RDD cannot be implemented on women. Thus, using RDD, we can check the robustness of the DID estimates for young men, which say that the subsidy program did not have a meaningful effect on the employment probability of young men.

We perform the RDD exercise using three different age windows centered around the cutoff age level: 29-30, 28-31, and 27-32. In all of these regressions, we find negative but very small and statistically insignificant estimates. This suggests that our DID estimates about the impact of the subsidy program on the employment probabilities of young men are robust; but, it does not say anything about the robustness of our estimates on the employment probabilities of women. So, RDD can offer only a partial robustness test due to the nature of the subsidy program.

\section{Concluding Remarks}

In this paper, we use micro-level labor market data to identify the employment effects of a employer-side hiring subsidy scheme implemented in Turkey in the post-2008 period. The subsidy program exogenously places older men (of age 30 and above) into the control group and the rest of the workers into the treatment group. We employ a difference-in-differences procedure to identify the causal effect of the program. We find that the program imposes an asymmetric effect across the treatment sub-groups, although, on aggregate, there seems to exist no statistically significant effect. In particular, the effect is more pronounced for older women, while a weaker positive effect is observed for younger women, and no effect is detected for younger men. We also document that the effect of the program is subject to a further layer of heterogeneity within the sub-groups. To be concrete, we show that, among older women, the program has been mostly effective on low-educated and/or low-skill individuals.

To summarize, our paper estimates the causal effect of a targeted employer-side hiring subsidy program. Evidence on employee-side subsidies is vast, which suggest that these policies are

considerably effective in increasing the employment prospects of the workers in the target groups. The evidence on the effectiveness of the employer-side subsidy schemes, however, is 
much scarce. It is also not so clear how they operate under alternative institutional settings. Our estimates suggest that the effects of the program implemented in Turkey exhibit a substantial degree of heterogeneity. This implies that labor demand elasticities are potentially different across the treatment subgroups and, therefore, the program might yield different effects if the target groups are altered. 


\section{References}

Ayhan, S. H. (2013): "Do Non-wage Cost Rigidities Slow Down Employment? Evidence from Turkey," IZA Journal of Labor Policy, 2, 1-23.

Baslevent, C. And O. Onaran (2003): “Are Turkish Wives More Likely to Become Added or Discouraged Workers?" Labour, 17, 439-458.

Behagel, L., B. Crepon, And B. Sedillot (2008): "The Perverse Effects of Partial Employment Protection Reform: The Case of French Older Workers," Journal of Public Economics, 92, 696-721.

Betcherman, G., N. M. Daysal, And P. Carmen (2010): "Do Employment Subsidies Work? Evidence from Regionally Targeted Subsidies in Turkey," Labour Economics, 17, $710-722$.

Blundell, R., M. Costa Dias, C. Meghir, and J. van Reenen (2004): "Evaluating the Employment Impact of a Mandatory Job Search Program," Journal of the European Economic Association, 2, 569-606.

Boockmann, B., T. Zwick, A. Ammermuller, And M. Maier (2012): "Do Hiring Subsidies Reduce Unemployment among the Elderly? Evidence from Natural Experiments," Journal of the European Economic Association, 10, 735-764.

Cheron, A., J.-O. Hairault, And F. Langot (2008): "A Quantitative Evaluation of Payroll Tax Subsidies for Low-Wage Workers: An Equilibrium Search Approach," Journal of Public Economics, 92, 817-843.

Crepon, B. And R. Desplatz (2002): "Evaluating the Effects of Payroll Tax Subsidies for Low Wage Workers," Unpublished Manuscript, CREST-INSEE.

De Giorgi, G. (2005): "The New Deal for Young People, Five Years On," Fiscal Studies, $26,371-383$.

Deidda, M., A. Di Liberto, M. Foddi, And G. Sulis (2015): "Employment Subsidies, 
Informal Economy and Women's Transition into Work in a Depressed Area: Evidence from a Matching Approach," IZA Journal of Labor Policy, 4, 1-25.

Goos, M. And J. Konings (2007): “The Impact of Payroll Tax Reductions on Employment and Wages: A Natural Experiment Using Firm Level Data," LICOS Discussion Papers \#17807.

Gruber, J. (1997): "The Incidence of Payroll Taxation: Evidence from Chile," Journal of Labor Economics, 15, S72-S101.

Huttunen, K., J. Pirtilla, And R. Uusitalo (2013): "The Employment Effects of Low-Wage Subsidies," Journal of Public Economics, 97, 49-60.

Kaldor, N. (1936): "Wage Subsidies as a Remedy for Unemployment," Journal of Political Economy, 44, 721-742.

Katz, L. F. (1998): "Wage Subsidies for the Disadvantaged," in Generating Jobs: How to Increase Demand for Less-Skilled Workers, ed. by R. B. Freeman and P. Gottschalk, New York, NY: The Russell Sage Foundation, chap. 1, 21-53.

Kluve, J. (2010): "The Effectiveness of European Active Labor Market Programs," Labour Economics, 17, 904-918.

Korkeamaki, O. R. And R. Uusitalo (2009): "Employment and Wage Effects of a PayrollTax Cut: Evidence from a Regional Experiment," International Tax and Public Finance, $16,753-772$.

Kramarz, F. And T. Philippon (2001): "The Impact of Differential Payroll Tax Subsidies on Minimum Wage Employment," Journal of Public Economics, 82, 115-146.

Malinvaud, E. (1998): "Les cotisations sociales à la charge des employeurs: Analyse economique," Unpublished manuscript, PASS.

NEAL, D. (1999): "The Complexity of Job Mobility among Young Men," Journal of Labor Economics, 17, 237-261. 
Orszag, M. J. AND D. J. SnOwer (2003): "Designing Employment Subsidies," Labour Economics, 10, 557-572.

Phelps, E. S. (1994): "Low-Wage Employment Subsidies versus the Welfare State," American Economic Review, 84, 54-58.

Snower, D. J. (1994): "Converting Unemployment Benefits into Employment Subsidies," American Economic Review, 84, 65-70.

TAyfur, M. D. And M. G. Kirdar (2011): “A Cohort Analysis of Women's Labor Market Participation in Turkey," Economic Research Forum Conference Paper.

UysaL, G. (2013): "Incentives Increase Formal Female Employment," Unpublished manuscript, Bahcesehir University. 


\section{A Data Appendix}

This appendix will summarize the related survey data and modifications to them when applicable.

- Employed: A binary variable taking the value of 1 if working and 0 otherwise.

- Subsidy: A binary variable taking the value of 1 for 2008-2012 and 0 if 2004-2007.

- Treatment: A binary variable taking the value of 1 if male of age $30 \&$ above and 0 otherwise.

- Gender: A binary variable taking the value 1 if male and 0 otherwise.

- Marital Status: A binary variable taking the value 1 if married and 0 otherwise.

- Education Status: 4 dummy variables constructed as follows: no degree; primary education; secondary education; and college education \& above.

- Industry Groups: A set of 99 industry dummies constructed based on the NACE Rev.2 classification.

- Occupation Groups: 9 dummy variables constructed based on the ISCO-88 classification as follows: senior officials and managers; professionals; technicians and associate professionals; clerks; service workers and shop and market sales workers; skilled agricultural and fishery workers; craft and related trades workers; plant and machine operators and assemblers; and elementary occupations.

- Region: 26 dummy variables constructed based on the NUTS2-level classification. 
Relative Employment Outcomes of Females and Young Males Before \& After the Subsidy (Probit Marginal Effects)

\begin{tabular}{lccc}
\hline \hline \multicolumn{1}{l}{ Dependent Variable $=\mathbf{1}$ if employed, } & $\mathbf{0}$ otherwise & & \\
\hline \multicolumn{1}{l}{ Variable } & {$[\mathbf{1}]$} & {$[\mathbf{2}]$} & {$[\mathbf{3}]$} \\
\hline Treatment Group $\times$ Subsidy & $0.0168^{* * *}$ & 0.0125 & 0.0128 \\
& $(0.0035)$ & $(0.0105)$ & $(0.0104)$ \\
Treatment Group $\times$ Regional Unemp. & $0.0034^{* *}$ & $0.0035^{*}$ & $0.0036^{* *}$ \\
& $(0.0017)$ & $(0.0018)$ & $(0.0018)$ \\
Regional Unemp. & $-0.0057^{* * *}$ & $-0.0058^{* * *}$ & $-0.0087^{* * *}$ \\
& $(0.0016)$ & $(0.0017)$ & $(0.0012)$ \\
\hline \hline Controls & Yes & Yes & Yes \\
Region Fixed Effects & Yes & Yes & Yes \\
Year Fixed Effects & Yes & Yes & Yes \\
Linear Time Trend for Treatment Group & No & Yes & Yes \\
Region-Year Effects & No & No & Yes \\
\hline \# of Observations & $2,089,277$ & $2,089,277$ & $2,089,277$ \\
\hline \hline
\end{tabular}

Table 2: Notes: (1) Our data cover all individuals of age 18-55 surveyed in the annual Turkish Household Labor Force Survey micro-level files. (2) Estimates reported are the probit marginal effects. (3) Subsidy is a dummy variable taking 1 for years 2008-2012 and 0 for 2004-2007. (4) The treatment group is defined as all females regardless of age AND males less than 30 years old. (5) Control variables include education categories, marital status, age, rural-urban status, regional unemployment rates, and their interactions with the treatment group. (6) Robust standard errors clustered for NUTS2-level regions are reported in parentheses. ***, **, and * indicate significance levels at 1 percent, 5 percent, and 10 percent, respectively. 
Relative Employment Outcomes of Females and Young Males Before \& After the Subsidy (Probit Marginal Effects)

\begin{tabular}{lccc}
\hline \hline \multicolumn{2}{l}{ Dependent Variable $=\mathbf{1}$ if employed, $\mathbf{0}$ otherwise } & & \\
\hline Variable & {$[\mathbf{1}]$} & {$[\mathbf{2}]$} & {$[\mathbf{3}]$} \\
\hline Female $\times$ Subsidy & $0.0443^{* * *}$ & 0.0229 & $0.0224^{*}$ \\
Male $<30 \times$ Subsidy & $(0.0049)$ & $(0.0132)$ & $(0.0135)$ \\
& $-0.0167^{* *}$ & 0.0028 & 0.0041 \\
Female $\times$ Regional Unemp. & $(0.0069)$ & $(0.0159)$ & $(0.0157)$ \\
& 0.0019 & 0.0024 & 0.0024 \\
Male $<30 \times$ Regional Unemp. & $(0.0027)$ & $(0.0028)$ & $(0.0028)$ \\
& 0.0034 & 0.0031 & 0.0031 \\
Regional Unemp. & $(0.0023)$ & $(0.0024)$ & $(0.0024)$ \\
& $-0.0055^{* * *}$ & $-0.0056^{* * *}$ & $-0.0076^{* * *}$ \\
\hline \hline Controls & $(0.0018)$ & $(0.0019)$ & $(0.0014)$ \\
Region Fixed Effects & Yes & Yes & Yes \\
Year Fixed Effects & Yes & Yes & Yes \\
Linear Time Trend for Treatment Group & Yes & Yes & Yes \\
Region-Year Effects & No & Yes & Yes \\
\hline \# of Observations & $2,089,277$ & No & Yes \\
\hline \hline
\end{tabular}

Table 3: Notes: (1) Our data cover all individuals of age 18-55 surveyed in the annual Turkish Household Labor Force Survey micro-level files. (2) Estimates reported are the probit marginal effects. (3) Subsidy is a dummy variable taking 1 for years 2008-2012 and 0 for 2004-2007. (4) The treatment group is defined as all females regardless of age AND males less than 30 years old. (5) Control variables include education categories, marital status, age, rural-urban status, regional unemployment rates, and their interactions with the treatment group. (6) Robust standard errors clustered for NUTS2-level regions are reported in parentheses. ***, **, and * indicate significance levels at 1 percent, 5 percent, and 10 percent, respectively. 


\begin{tabular}{|c|c|c|c|}
\hline \multicolumn{4}{|c|}{ Dependent Variable $=1$ if employed, $=0$ otherwise } \\
\hline Variable & {$[1]$} & {$[2]$} & {$[3]$} \\
\hline \multirow[t]{2}{*}{ Male $<30 \times$ Subsidy } & $-0.0186^{* * *}$ & -0.0033 & -0.0046 \\
\hline & $(0.0071)$ & $(0.0161)$ & $(0.0160)$ \\
\hline \multirow{2}{*}{ Female $\geq 30 \times$ Subsidy } & $0.0683^{* * *}$ & $0.0226^{*}$ & $0.0248^{*}$ \\
\hline & $(0.0057)$ & $(0.0125)$ & $(0.0128)$ \\
\hline \multirow[t]{2}{*}{ Female $<30 \times$ Subsidy } & $0.0154^{* *}$ & 0.0221 & 0.0226 \\
\hline & $(0.0068)$ & $(0.0172)$ & $(0.0173)$ \\
\hline \multirow[t]{2}{*}{ Male $<30 \times$ Regional Unemp. } & 0.0031 & 0.0028 & 0.0029 \\
\hline & $(0.0023)$ & $(0.0024)$ & $(0.0024)$ \\
\hline \multirow[t]{2}{*}{ Female $\geq 30 \times$ Regional Unemp. } & 0.0011 & 0.0011 & 0.0011 \\
\hline & $(0.0028)$ & $(0.0029)$ & $(0.0029)$ \\
\hline \multirow[t]{2}{*}{ Female $<30 \times$ Regional Unemp. } & 0.0034 & 0.0033 & 0.0034 \\
\hline & $(0.0032)$ & $(0.0034)$ & $(0.0034)$ \\
\hline \multirow[t]{2}{*}{ Regional Unemp. } & $-0.0054^{* * *}$ & $-0.0055^{* * *}$ & $-0.0075^{* * *}$ \\
\hline & $(0.0018)$ & $(0.0019)$ & $(0.0014)$ \\
\hline Controls & Yes & Yes & Yes \\
\hline Region Fixed Effects & Yes & Yes & Yes \\
\hline Year Fixed Effects & Yes & Yes & Yes \\
\hline Linear Time Trend for Treatment Group & No & Yes & Yes \\
\hline Region-Year Effects & No & No & Yes \\
\hline \# of Observations & $2,089,277$ & $2,089,277$ & $2,089,277$ \\
\hline
\end{tabular}

Table 4: Notes: (1) Our data cover all individuals of age 18-55 surveyed in the annual Turkish Household Labor Force Survey micro-level files. (2) Estimates reported are the probit marginal effects. (3) Subsidy is a dummy variable taking 1 for years 2008-2012 and 0 for 2004-2007. (4) The treatment group is defined as all females regardless of age AND males less than 30 years old. (5) Control variables include education categories, marital status, age, rural-urban status, regional unemployment rates, and their interactions with the treatment group. (6) Robust standard errors clustered for NUTS2-level regions are reported in parentheses. ${ }^{* * *}$, **, and * indicate significance levels at 1 percent, 5 percent, and 10 percent, respectively. 


\section{Relative Employment Outcomes of Females and Young Males Before \& After the Subsidy}

(Probit Marginal Effects)

\begin{tabular}{|c|c|c|c|c|c|c|}
\hline \multicolumn{7}{|c|}{ Dependent Variable $=1$ if employed, $=0$ otherwise } \\
\hline Variable & {$[1]$} & {$[2]$} & {$[3]$} & {$[4]$} & [5] & {$[6]$} \\
\hline Treatment Group $\times$ Sub. & $\begin{array}{c}0.0359 * * * \\
(0.0104)\end{array}$ & $\begin{array}{c}0.0364^{* * *} \\
(0.0102)\end{array}$ & & & & \\
\hline Female $\times$ Sub & & & $\begin{array}{c}0.0379 * * * \\
(0.0134)\end{array}$ & $\begin{array}{c}0.0400^{* * *} \\
(0.0134)\end{array}$ & & \\
\hline Male $<30 \times$ Sub & & & $\begin{array}{c}0.0123 \\
(0.0160)\end{array}$ & $\begin{array}{c}0.0127 \\
(0.0161)\end{array}$ & $\begin{array}{c}0.0114 \\
(0.0161)\end{array}$ & $\begin{array}{c}0.0117 \\
(0.0162)\end{array}$ \\
\hline Female $\geq 30 \times$ Sub & & & & & $\begin{array}{c}0.0457^{* * *} \\
(0.0141)\end{array}$ & $\begin{array}{c}0.0480^{* * *} \\
(0.0139)\end{array}$ \\
\hline Female $<30 \times$ Sub & & & & & $\begin{array}{c}0.0293^{*} \\
(0.0151)\end{array}$ & $\begin{array}{c}0.0311^{* *} \\
(0.0152)\end{array}$ \\
\hline Treat. Group × Reg. Unemp. & $\begin{array}{c}0.0040^{* * *} \\
(0.0011)\end{array}$ & $\begin{array}{c}0.0042^{* * *} \\
(0.0012)\end{array}$ & & & & \\
\hline Fem. $\times$ Regional Unemp. & & & $\begin{array}{l}0.0037^{*} \\
(0.0022)\end{array}$ & $\begin{array}{c}0.0039^{*} \\
(0.0022)\end{array}$ & & \\
\hline Male $<30 \times$ Reg. Unemp. & & & $\begin{array}{c}0.0015 \\
(0.0009)\end{array}$ & $\begin{array}{c}0.0015 \\
(0.0010)\end{array}$ & $\begin{array}{c}0.0014 \\
(0.0009)\end{array}$ & $\begin{array}{c}0.0015 \\
(0.0010)\end{array}$ \\
\hline Fem. $\geq 30 \times$ Reg. Unemp. & & & & & $\begin{array}{c}0.0018 \\
(0.0027)\end{array}$ & $\begin{array}{c}0.0019 \\
(0.0027)\end{array}$ \\
\hline Fem. $<30 \times$ Reg. Unemp. & & & & & $\begin{array}{c}0.0056^{* * *} \\
(0.0021)\end{array}$ & $\begin{array}{c}0.0058^{* * *} \\
(0.0021)\end{array}$ \\
\hline Regional Unemp. & $\begin{array}{c}-0.0075^{* * *} \\
(0.0014) \\
\end{array}$ & $\begin{array}{c}-0.0056^{* * *} \\
(0.0011) \\
\end{array}$ & $\begin{array}{l}-0.0014^{*} \\
(0.0008) \\
\end{array}$ & $\begin{array}{c}-0.0066^{* * *} \\
(0.0018) \\
\end{array}$ & $\begin{array}{c}-0.0068^{* * *} \\
(0.0023) \\
\end{array}$ & $\begin{array}{c}-0.0042^{* *} \\
(0.0019) \\
\end{array}$ \\
\hline Controls & Yes & Yes & Yes & Yes & Yes & Yes \\
\hline Region Fixed Effects & Yes & Yes & Yes & Yes & Yes & Yes \\
\hline Year Fixed Effects & Yes & Yes & Yes & Yes & Yes & Yes \\
\hline Linear Trend for Treat. Gr. & Yes & Yes & Yes & Yes & Yes & Yes \\
\hline Region-Year Effects & No & Yes & No & Yes & No & Yes \\
\hline \# of Observations & 685,932 & 685,932 & 685,932 & 685,932 & 685,932 & 685,932 \\
\hline
\end{tabular}

Table 5: Notes: This table repeats the estimates reported in Tables (2) - (4) for the individuals of age 25-35. Robust standard errors clustered for NUTS2-level regions are reported in parentheses. ${ }^{* * *},{ }^{* *}$, and ${ }^{*}$ indicate significance levels at 1 percent, 5 percent, and 10 percent, respectively. 


\section{Relative Employment Outcomes of Females and Young Males Before \& After the Subsidy}

(Probit Marginal Effects)

\begin{tabular}{|c|c|c|c|c|c|c|}
\hline \multicolumn{7}{|c|}{ Dependent Variable $=1$ if employed, $=0$ otherwise } \\
\hline Variable & {$[1]$} & {$[2]$} & {$[3]$} & {$[4]$} & {$[5]$} & {$[6]$} \\
\hline Treatment Group $\times$ Sub & $\begin{array}{c}0.0294^{* *} \\
(0.0146)\end{array}$ & $\begin{array}{c}0.0299^{* *} \\
(0.0146)\end{array}$ & & & & \\
\hline Female $\times$ Sub & & & $\begin{array}{c}0.0371^{* *} \\
(0.0177)\end{array}$ & $\begin{array}{c}0.0397^{* *} \\
(0.0185)\end{array}$ & & \\
\hline Male $<30 \times$ Sub & & & $\begin{array}{c}0.0029 \\
(0.0188)\end{array}$ & $\begin{array}{c}0.0028 \\
(0.0186)\end{array}$ & $\begin{array}{c}0.0028 \\
(0.0188)\end{array}$ & $\begin{array}{c}0.0027 \\
(0.0186)\end{array}$ \\
\hline Female $\geq 30 \times$ Sub & & & & & $\begin{array}{c}0.0388^{*} \\
(0.0213)\end{array}$ & $\begin{array}{l}0.0412^{*} \\
(0.0219)\end{array}$ \\
\hline Female $<30 \times$ Sub & & & & & $\begin{array}{c}0.0352^{* *} \\
(0.0173)\end{array}$ & $\begin{array}{c}0.0379 * * \\
(0.0183)\end{array}$ \\
\hline Treat. Group × Reg. Unemp. & $\begin{array}{c}0.0046^{* *} \\
(0.0019)\end{array}$ & $\begin{array}{c}0.0048^{* *} \\
(0.0019)\end{array}$ & & & & \\
\hline Fem. $\times$ Regional Unemp. & & & $\begin{array}{c}0.0046^{*} \\
(0.0025)\end{array}$ & $\begin{array}{l}0.0049^{*} \\
(0.0025)\end{array}$ & & \\
\hline Male $<30 \times$ Reg. Unemp. & & & $\begin{array}{c}0.0013 \\
(0.0012)\end{array}$ & $\begin{array}{c}0.0014 \\
(0.0012)\end{array}$ & $\begin{array}{c}0.0013 \\
(0.0012)\end{array}$ & $\begin{array}{c}0.0014 \\
(0.0012)\end{array}$ \\
\hline Fem. $\geq 30 \times$ Reg. Unemp. & & & & & $\begin{array}{c}0.0034 \\
(0.0030)\end{array}$ & $\begin{array}{c}0.0037 \\
(0.0031)\end{array}$ \\
\hline Fem. $<30 \times$ Reg. Unemp. & & & & & $\begin{array}{c}0.0056^{* *} \\
(0.0024)\end{array}$ & $\begin{array}{c}0.0059^{* *} \\
(0.0024)\end{array}$ \\
\hline Regional Unemp. & $\begin{array}{c}-0.0061^{* * *} \\
(0.0015)\end{array}$ & $\begin{array}{c}-0.0069^{* * *} \\
(0.0014)\end{array}$ & $\begin{array}{c}-0.0067^{* * *} \\
(0.0015)\end{array}$ & $\begin{array}{c}-0.0060^{* * *} \\
(0.0009)\end{array}$ & $\begin{array}{c}-0.0067^{* * *} \\
(0.0015) \\
\end{array}$ & $\begin{array}{c}-0.0060^{* * *} \\
(0.0009)\end{array}$ \\
\hline Controls & Yes & Yes & Yes & Yes & Yes & Yes \\
\hline Region Fixed Effects & Yes & Yes & Yes & Yes & Yes & Yes \\
\hline Year Fixed Effects & Yes & Yes & Yes & Yes & Yes & Yes \\
\hline Linear Trend for Treat. Gr. & Yes & Yes & Yes & Yes & Yes & Yes \\
\hline Region-Year Effects & No & Yes & No & Yes & No & Yes \\
\hline \# of Observations & 252,510 & 252,510 & 252,510 & 252,510 & 252,510 & 252,510 \\
\hline
\end{tabular}

Table 6: Notes: This table repeats the estimates reported in Tables (2) - (4) for the individuals of age 28-31. Robust standard errors clustered for NUTS2-level regions are reported in parentheses. ${ }^{* * *},{ }^{* *}$, and ${ }^{*}$ indicate significance levels at 1 percent, 5 percent, and 10 percent, respectively. 
Relative Employment Outcomes of Females and Young Males Before \& After the Subsidy Estimates by Education Categories (Probit Marginal Effects)

\begin{tabular}{|c|c|c|c|c|c|}
\hline \multicolumn{6}{|c|}{ Dependent Variable $=1$ if employed, $=0$ otherwise } \\
\hline Variable & {$[1]$} & {$[2]$} & {$[3]$} & {$[4]$} & [5] \\
\hline \multirow[t]{2}{*}{ Male $<30 \times$ Sub } & -0.0046 & $-0.0249^{* *}$ & -0.0083 & 0.0034 & -0.0008 \\
\hline & $(0.0160)$ & $(0.0106)$ & $(0.0143)$ & $(0.0180)$ & $(0.0274)$ \\
\hline \multirow[t]{2}{*}{ Female $\geq 30 \times$ Sub } & $0.0248^{*}$ & $0.0392^{* *}$ & $0.0291^{*}$ & $0.0279 *$ & $0.0263^{* *}$ \\
\hline & $(0.0128)$ & $(0.0186)$ & $(0.0162)$ & $(0.0148)$ & $(0.0117)$ \\
\hline \multirow[t]{2}{*}{ Female $<30 \times$ Sub } & 0.0226 & 0.0181 & 0.0230 & $0.0364^{*}$ & 0.0062 \\
\hline & $(0.0173)$ & $(0.0132)$ & $(0.0217)$ & $(0.0216)$ & $(0.0173)$ \\
\hline \multirow[t]{2}{*}{ Male $<30 \times$ Reg. Unemp. } & 0.0029 & 0.0008 & 0.0021 & 0.0001 & 0.0019 \\
\hline & $(0.0024)$ & $(0.0014)$ & $(0.0024)$ & $(0.0030)$ & $(0.0033)$ \\
\hline \multirow[t]{2}{*}{ Fem. $\geq 30 \times$ Reg. Unemp. } & 0.0011 & -0.0069 & -0.0008 & 0.0015 & 0.0038 \\
\hline & $(0.0029)$ & $(0.0028)$ & $(0.0030)$ & $(0.0029)$ & $(0.0016)$ \\
\hline \multirow[t]{2}{*}{ Fem. $<30 \times$ Reg. Unemp. } & 0.0034 & -0.0025 & 0.0012 & 0.0019 & $0.0053^{*}$ \\
\hline & $(0.0034)$ & $(0.0024)$ & $(0.0041)$ & $(0.0040)$ & $(0.0027)$ \\
\hline \multirow[t]{2}{*}{ Regional Unemp. } & $-0.0075^{* * *}$ & $-0.0056^{* * *}$ & $-0.0014^{*}$ & $-0.0077^{* * *}$ & $-0.0042^{* *}$ \\
\hline & $(0.0014)$ & $(0.0011)$ & $(0.0008)$ & $(0.0020)$ & $(0.0019)$ \\
\hline Controls & Yes & Yes & Yes & Yes & Yes \\
\hline Region Fixed Effects & Yes & Yes & Yes & Yes & Yes \\
\hline Year Fixed Effects & Yes & Yes & Yes & Yes & Yes \\
\hline Linear Trend for Treat. Gr. & Yes & Yes & Yes & Yes & Yes \\
\hline Region-Year Effects & Yes & Yes & Yes & Yes & Yes \\
\hline \# of Observations & $2,089,277$ & 159,131 & 832,745 & 584,426 & 199,541 \\
\hline
\end{tabular}

Table 7: Notes: This table reports estimates by education groups for the individuals of age 18-55. The first column reports the estimates for all education groups, second no degree, third primary education, fourth secondary education, and fifth college education \& above. Robust standard errors clustered for NUTS2-level regions are reported in parentheses. ${ }^{* * *},{ }^{* *}$, and ${ }^{*}$ indicate significance levels at 1 percent, 5 percent, and 10 percent, respectively. 
Relative Employment Outcomes of Females and Young Males Before \& After the Subsidy Estimates by Education Categories (Probit Marginal Effects)

\begin{tabular}{|c|c|c|c|c|c|}
\hline \multicolumn{6}{|c|}{ Dependent Variable $=1$ if employed, $=0$ otherwise } \\
\hline Variable & {$[1]$} & {$[2]$} & {$[3]$} & {$[4]$} & {$[5]$} \\
\hline \multirow[t]{2}{*}{ Male $<30 \times$ Sub } & 0.0117 & -0.0060 & -0.0011 & 0.0138 & -0.0133 \\
\hline & $(0.0162)$ & $(0.0233)$ & $(0.0180)$ & $(0.0186)$ & $(0.0167)$ \\
\hline \multirow[t]{2}{*}{ Female $\geq 30 \times$ Sub } & $0.0480^{* * *}$ & $0.0526^{*}$ & $0.0595^{* *}$ & $0.0302^{*}$ & 0.0192 \\
\hline & $(0.0139)$ & $(0.0317)$ & $(0.0233)$ & $(0.0166)$ & $(0.0239)$ \\
\hline \multirow[t]{2}{*}{ Female $<30 \times$ Sub } & $0.0311^{* *}$ & 0.0587 & 0.0296 & $0.0496^{* *}$ & 0.0138 \\
\hline & $(0.0152)$ & $(0.0409)$ & $(0.0259)$ & $(0.0203)$ & $(0.0142)$ \\
\hline \multirow[t]{2}{*}{ Male $<30 \times$ Reg. Unemp. } & 0.0015 & 0.0005 & 0.0017 & -0.0005 & 0.0019 \\
\hline & $(0.0010)$ & $(0.0014)$ & $(0.0012)$ & $(0.0030)$ & $(0.0019)$ \\
\hline \multirow{2}{*}{ Fem. $\geq 30 \times$ Reg. Unemp. } & 0.0019 & $-0.0065^{* *}$ & -0.0020 & 0.0024 & 0.0034 \\
\hline & $(0.0027)$ & $(0.0031)$ & $(0.0040)$ & $(0.0028)$ & $(0.0021)$ \\
\hline \multirow[t]{2}{*}{ Fem. $<30 \times$ Reg. Unemp. } & $0.0058^{* * *}$ & -0.0032 & 0.0025 & 0.0007 & $0.0069 * * *$ \\
\hline & $(0.0021)$ & $(0.0031)$ & $(0.0035)$ & $(0.0034)$ & $(0.0015)$ \\
\hline \multirow[t]{2}{*}{ Regional Unemp. } & $-0.0070^{* * *}$ & $-0.0026^{* *}$ & -0.0004 & $-0.0076^{* * *}$ & $-0.0031^{* *}$ \\
\hline & $(0.0006)$ & $(0.0012)$ & $(0.0009)$ & $(0.0019)$ & $(0.0014)$ \\
\hline Controls & Yes & Yes & Yes & Yes & Yes \\
\hline Region Fixed Effects & Yes & Yes & Yes & Yes & Yes \\
\hline Year Fixed Effects & Yes & Yes & Yes & Yes & Yes \\
\hline Linear Trend for Treat. Gr. & Yes & Yes & Yes & Yes & Yes \\
\hline Region-Year Effects & Yes & Yes & Yes & Yes & Yes \\
\hline \# of Observations & 685,932 & 35,206 & 282,942 & 381,915 & 76,653 \\
\hline
\end{tabular}

Table 8: Notes: This table repeats the estimates reported in Table (7) for the individuals of age 25-35. The first column reports the estimates for all education groups, second no degree, third primary education, fourth secondary education, and fifth college education \& above. Robust standard errors clustered for NUTS2-level regions are reported in parentheses. ${ }^{* * *},{ }^{* *}$, and ${ }^{*}$ indicate significance levels at 1 percent, 5 percent, and 10 percent, respectively. 
Relative Employment Outcomes of Females and Young Males Before \& After the Subsidy Estimates by Predicted Wage Groups (Probit Marginal Effects)

\begin{tabular}{lccccc}
\hline \hline \multicolumn{1}{l}{ Dependent Variable $=\mathbf{1}$ if employed, $=\mathbf{0}$ otherwise } & & \\
\hline Variable & {$[\mathbf{1}]$} & {$[\mathbf{2}]$} & {$[\mathbf{3}]$} & {$[\mathbf{4}]$} & {$[\mathbf{5}]$} \\
\hline Male $<30 \times$ Sub. & -0.0046 & -0.0145 & $0.0483^{* *}$ & 0.0236 & -0.0094 \\
& $(0.0160)$ & $(0.0262)$ & $(0.0199)$ & $(0.0162)$ & $(0.0351)$ \\
Female $\geq 30 \times$ Sub. & $0.0248^{*}$ & -0.0015 & $0.0688^{* *}$ & $0.0654^{* * *}$ & 0.0168 \\
& $(0.0128)$ & $(0.0297)$ & $(0.0288)$ & $(0.0229)$ & $(0.0170)$ \\
Female $<30 \times$ Sub. & 0.0226 & 0.0052 & $0.1080^{* * *}$ & $0.0590^{* *}$ & 0.0123 \\
& $(0.0173)$ & $(0.0305)$ & $(0.0290)$ & $(0.0256)$ & $(0.0198)$ \\
Male $<30 \times$ Reg. Unemp. & 0.0029 & -0.0038 & $-0.0047^{* *}$ & $-0.0043^{*}$ & 0.0038 \\
& $(0.0024)$ & $(0.0028)$ & $(0.0024)$ & $(0.0023)$ & $(0.0046)$ \\
Fem. $\geq 30 \times$ Reg. Unemp. & 0.0011 & $-0.0080^{* * *}$ & $-0.0097^{* *}$ & 0.0052 & 0.0019 \\
& $(0.0029)$ & $(0.0031)$ & $(0.0045)$ & $(0.0054)$ & $(0.0024)$ \\
Fem. $<30 \times$ Reg. Unemp. & 0.0034 & $-0.0083^{* *}$ & $-0.0102^{*}$ & $0.0095^{* *}$ & $0.0045^{* *}$ \\
& $(0.0034)$ & $(0.0034)$ & $(0.0057)$ & $(0.0041)$ & $(0.0021)$ \\
Regional Unemp. & $-0.0075^{* * *}$ & $-0.0108^{* * *}$ & $-0.0115^{* * *}$ & -0.0021 & $-0.0081^{* * *}$ \\
& $(0.0014)$ & $(0.0027)$ & $(0.0019)$ & $(0.0015)$ & $(0.0012)$ \\
\hline \hline Controls & Yes & Yes & Yes & Yes & Yes \\
Region Fixed Effects & Yes & Yes & Yes & Yes & Yes \\
Year Fixed Effects & Yes & Yes & Yes & Yes & Yes \\
Linear Trend for Treat. Gr. & Yes & Yes & Yes & Yes & Yes \\
Region-Year Effects & Yes & Yes & Yes & Yes & Yes \\
\hline \# of Observations & $2,089,277$ & 490,811 & 519,533 & 513,197 & 565,290 \\
\hline \hline
\end{tabular}

Table 9: Notes: This table reports estimates by predicted wage groups for the individuals of age 18-55. The first column reports the estimates for all wage groups, second 1st quartile, third 2nd quartile, fourth 3rd quartile, and fifth 4th quartile. Robust standard errors clustered for NUTS2-level regions are reported in parentheses. ${ }^{* *},{ }^{* *}$, and ${ }^{*}$ indicate significance levels at 1 percent, 5 percent, and 10 percent, respectively. 
Relative Employment Outcomes of Females and Young Males Before \& After the Subsidy Estimates by Predicted Wage Groups (Probit Marginal Effects)

\begin{tabular}{lccccc}
\hline \hline \multicolumn{1}{l}{ Dependent Variable $=\mathbf{1}$ if employed, $=\mathbf{0}$ otherwise } & & \\
\hline Variable & {$[\mathbf{1}]$} & {$[\mathbf{2}]$} & {$[\mathbf{3}]$} & {$[\mathbf{4}]$} & {$[\mathbf{5}]$} \\
\hline Male $<30 \times$ Sub. & 0.0117 & -0.0097 & $0.0623^{*}$ & 0.0054 & -0.0083 \\
& $(0.0162)$ & $(0.0238)$ & $(0.0348)$ & $(0.0187)$ & $(0.0249)$ \\
Female $\geq 30 \times$ Sub. & $0.0480^{* * *}$ & 0.0349 & $0.1040^{* * *}$ & $0.0372^{*}$ & $0.0291^{*}$ \\
& $(0.0139)$ & $(0.0395)$ & $(0.0359)$ & $(0.0216)$ & $(0.0151)$ \\
Female $<30 \times$ Sub. & $0.0311^{* *}$ & 0.0153 & $0.0672^{*}$ & $0.0648^{*}$ & $0.0236^{*}$ \\
& $(0.0152)$ & $(0.0409)$ & $(0.0390)$ & $(0.0347)$ & $(0.0123)$ \\
Male $<30 \times$ Reg. Unemp. & 0.0015 & $-0.0047^{* *}$ & $-0.0047^{* * *}$ & -0.0007 & 0.0034 \\
& $(0.0010)$ & $(0.0022)$ & $(0.0017)$ & $(0.0017)$ & $(0.0028)$ \\
Fem. $\geq 30 \times$ Reg. Unemp. & 0.0019 & $-0.0093^{* *}$ & $-0.0117^{* *}$ & -0.0006 & 0.0015 \\
& $(0.0027)$ & $(0.0037)$ & $(0.0053)$ & $(0.0041)$ & $(0.0021)$ \\
Fem. $<30 \times$ Reg. Unemp. & $0.0059^{* * *}$ & $-0.0092^{* *}$ & -0.0071 & $0.0086^{* * *}$ & $0.0047^{* * *}$ \\
& $(0.0021)$ & $(0.0037)$ & $(0.0063)$ & $(0.0032)$ & $(0.0016)$ \\
Regional Unemp. & $-0.0070^{* * *}$ & $0.0162^{* * *}$ & 0.0017 & $-0.0079^{* * *}$ & $-0.0047^{* * *}$ \\
& $(0.0006)$ & $(0.0026)$ & $(0.0015)$ & $(0.0010)$ & $(0.0014)$ \\
\hline \hline Controls & Yes & Yes & Yes & Yes & Yes \\
Region Fixed Effects & Yes & Yes & Yes & Yes & Yes \\
Year Fixed Effects & Yes & Yes & Yes & Yes & Yes \\
Linear Trend for Treat. Gr. & Yes & Yes & Yes & Yes & Yes \\
Region-Year Effects & Yes & Yes & Yes & Yes & Yes \\
\hline \# of Observations & 685,932 & 138,604 & 168,290 & 178,442 & 200,395 \\
\hline \hline
\end{tabular}

Table 10: Notes: This table repeats the estimates reported in Table (9) for the individuals of age 25-35. The first column reports the estimates for all wage groups, second 1st quartile, third 2nd quartile, fourth 3rd quartile, and fifth 4th quartile. Robust standard errors clustered for NUTS2-level regions are reported in parentheses. ${ }^{* *},{ }^{* *}$, and ${ }^{*}$ indicate significance levels at 1 percent, 5 percent, and 10 percent, respectively. 